\title{
O PONTO DE VISTA DETERMINA O OBJETO: UMA LEITURA MATERIALISTA POSSÍVEL DO OBJETO DE ESTUDO CONCEBIDO POR SAUSSURE EM SUA TEORIZAÇÃO
}

\author{
ÉLCIO ALOISIO FRAGOSO ${ }^{1}$ \\ Fundação Universidade Federal de Rondônia \\ Campus - BR 364, Km 9,5 - 76801-059 - Porto Velho - RO - Brasil \\ elciofragosodunir.br
}

\begin{abstract}
Resumo. Neste artigo, filiando-nos à perspectiva teórico-metodológica da Análise de Discurso, conforme os trabalhos de Michel Pêcheux, na França, e de Eni Orlandi, no Brasil, articulada à metodologia da História das Ideias Linguísticas, procuramos trazer uma reflexão sobre a prática teórica como prática discursiva, produzida pela teoria linguística de Chomsky, considerando a história de suas ideias basilares. Desse ponto de vista, as teorias linguísticas são processos discursivos que se realizam sob determinadas condições históricas, colocando em funcionamento efeitos de sentido, sem que se questione, de fato, a constituição desses efeitos, decorrendo, portanto, na negação da ideologia em suas práticas (teóricas).

Palavras-chave: análise de discurso; ideologia; língua; prática discursiva; teorias linguísticas.
\end{abstract}

\begin{abstract}
In this article, we proposed to do a reflection on the theoretical practice, as a discursive practice, produced by linguistic theory of Chomsky, considering the history of their basic ideas. The theoretical framework adopted in this study is the French school of Discourse of Analysis, based on theoretical concepts and ideas of Michel Pêcheux and Eni Orlandi, articulated at methodology of History of Linguistic Ideas. From this perspective, the linguistic theories are discursive processes which are accomplished in the base of the language, under certain conditions, putting in functioning certain effects of sense, without any questioning, in fact, of the constitution of these effects not even material existence of ideology.
\end{abstract}

Keywords: discourse analysis; ideology; language; discursive practice; linguistic theories.

\footnotetext{
${ }^{1}$ Doutor em Linguística pela Universidade Estadual de Campinas. Docente na Universidade Federal de Rondônia (UNIR), onde atua na graduação e nos Mestrados Acadêmicos em Letras e em História e Estudos Culturais. http://lattes.cnpq.br/0480649113661832.
} 


\section{Introdução}

O título deste artigo dialoga com uma afirmação de Saussure, em relação à definição e à concepção do objeto de estudo da Linguística, em seu Curso de Linguística Geral, postumamente publicado por dois de seus alunos, em 1916. Inicialmente, podemos dizer que a Linguística materializa um discurso científico sobre a (s) língua (s) e isso, certamente, traz consequências importantes de serem analisadas no âmbito da história das ideais linguísticas. Em outras palavras, com a Linguística temos a constituição de um discurso científico sobre a (s) língua (s) e compreender o processo histórico de constituição dessas ideias nos coloca numa posição materialista que implica em outra forma de conceber a (s) ciência (s).

Temos com o discurso científico, teorizado pela Linguística, por meio de Saussure, a constituição de um objeto de conhecimento, determinado por um discurso positivista que institui a língua como um todo, efeito de sentido, produzido pela cientificidade, instaurado pela Linguística.

A reflexão que faremos nesse trabalho inscreve-se numa forma de compreender a prática científica num quadro de questões que problematiza essa própria prática, procurando estabelecer relações entre prática teórica, sujeito e ideologia. Uma ciência, para nós, é uma teorização de seu objeto (ALTHUSSER, 1991, p. 64).

Para desenvolvermos qualquer reflexão teórica ${ }^{2}$, precisamos estabelecer princípios e procedimentos que determinarão a constituição dessas ideias. Mais que isso, de uma posição materialista, devemos entender que a produção do conhecimento não se dá fora das relações sociais de produção. Assim, a constituição de uma teoria deve ser pensada relativamente às práticas sociais, dentre as quais a prática científica não é uma prática qualquer, é por meio dela que os indivíduos são interpelados em sujeitos pesquisadores, cientistas etc.

No caso, o presente artigo busca apresentar uma reflexão sobre teorias, os métodos a elas relacionados, a fim de pensar a própria constituição dessas teorias (de suas ideias). Estamos nos referindo, especificamente, às ciências da linguagem e suas relações com a ideologia, ou seja, o nosso interesse aqui é o de compreender a constituição dessas discursividades científicas.

A nossa filiação à metodologia da história das ideias linguísticas se deve ao fato desta (metodologia) também considerar a história como fator determinante, incontornável para o estudo da constituição das ideias linguísticas. Nunes (2008), em seu artigo, "Uma articulação da análise de discurso com a história das ideias linguísticas", vai nos dizer que

Embora a chamada linguística moderna, tal como iniciada pelos comparatistas no século XIX e depois por Saussure no século XX, seja contemplada, ela não é considerada como o ponto de início das ciências da linguagem, que têm uma história bem mais longa e plural. Assim,

\footnotetext{
${ }^{2} \mathrm{E}$ aqui estamos falando, especificamente, do processo histórico de produção do conhecimento que se constitui nas práticas sociais, principalmente, na prática científica.
} 
quando utilizamos o adjetivo linguístico, ele se refere a qualquer saber produzido sobre a linguagem na história. (NUNES, 2008, p. 109)

Nossa questão nesse artigo é também a de compreender a prática científica como uma prática político-ideológica e, dessa forma, ela não é, como veremos (a partir dos estudos de Henry, 1992) uma prática qualquer. O conhecimento, portanto, não se produz, a não ser teórica, histórica e ideologicamente falando. O conhecimento não é algo neutro como encontramos no discurso positivista e cientificista da Linguística.

Um exemplo que podemos dar é a neutralidade científica, o efeito de cientificidade, que encontramos no discurso da Linguística, elaborado por Saussure. Uma reflexão dessa natureza só é possível quando nos colocamos na posição de querer compreender como o conhecimento é teoricamente construído, pois ele se produz sob formas históricas muito variadas, considerando as práticas sociais, as práticas científicas enquanto condições materiais para a sua existência, e que, por isso mesmo, essa discussão só se pode dar no nível teórico ${ }^{3}$. Trata-se, então, de uma forma de produzir conhecimento que leve em conta o processo histórico de produção desse conhecimento, isto é, o processo histórico de constituição das teorias linguística.

Dessa perspectiva, estamos filiados a uma posição que, ao refletir sobre a prática teórico-científica, o faz assumindo que dessa filiação, o nosso objeto de estudo é a própria história das ciências e a constituição de seus objetos de estudo.

A produção do conhecimento é sempre uma teorização do objeto de estudo. Não se tem como falar de ciência se não teoricamente, o que já constitui uma prática discursiva, nas práticas sociais. Toda teorização se dá a partir de certas formações discursivas que determinam o que pode e o que deve ser dito. Acreditamos que tenha ficado clara a nossa posição em relação à prática científica teórica enquanto prática ideológica.

Faremos a seguir algumas considerações de ordem epistemológica para situar nossa filiação teórica à metodologia da Análise de Discurso na linha de Michel Pêcheux e Eni Orlandi.

\section{A Linguística e a extensão irrefletida de seu domínio}

Tratar de todas as teorias linguísticas, da constituição de suas ideias, evidentemente, é uma tarefa ambiciosa demais para o espaço desse artigo. Entretanto, quando, em nosso texto, tematizamos as teorias linguísticas, não estamos com isso, igualmente, generalizando ou descuidando de suas especificidades históricas ${ }^{4}$, estamos

\footnotetext{
${ }^{3}$ Lembramos que não fazemos distinção entre teoria e prática, pois a própria teorização, enquanto prática científica, já é uma prática ideológica/discursiva.

${ }^{4}$ Essa é, aliás, a nossa tese defendida nesse artigo, a de que cada teoria linguística constitui uma teorização própria, é um processo discursivo próprio. E isso fica ainda mais instigante quando evocamos a metodologia da história das ciências como referência para tal estudo.
} 
apenas querendo explicitar o corte teórico-epistemológico que a Análise de Discurso realizou no domínio dos estudos linguísticos. Portanto, não se trata de pensar a Linguística como uma ciência uma, homogênea ${ }^{5}$, coisa que ela, realmente, não é. Queremos, sim, por outro lado, compreender as teorias linguísticas como processos discursivos, explicitando, dessa forma, a configuração ideológica na constituição do conhecimento científico. Fazse necessário, então, para melhor alcançarmos nossos objetivos neste trabalho, recortar uma teoria linguística específica para compreender o processo de constituição de suas ideias.

As ideias desenvolvidas, pelos estudiosos, através dos tempos, a respeito da questão das línguas vão constituindo em diferentes abordagens um material que relata sobre esta questão.

Estamos tratando aqui da produção do conhecimento, produção esta que é um processo histórico e que, portanto, devemos pensá-lo como uma prática social em que indivíduos concretos ( $c f$. ALTHUSSER apud HENRY, 1992) que, se não são os sujeitos, são pelo menos os agentes, agem na e sob a determinação das formas de existência histórica das relações sociais de produção e reprodução (processo de trabalho, divisão e organização do trabalho, processo de produção e reprodução, luta de classes etc.).

Dessa posição é que podemos afirmar, segundo Lecourt (1980), referindo-se à história real das ciências, que as teorias linguísticas, o conjunto delas, não constituem uma realidade homogênea, uma unidade dum todo indiferenciado.

Embora haja discursos, em particular nas ciências positivistas, que apregoam que o conhecimento seja algo que se produz na cabeça das pessoas, nossa posição, como analista de discurso, é a de que o conhecimento se constitui sócio-historicamente, em determinadas condições de produção.

Nesse sentido, podemos dizer que a Linguística é uma ciência construída pelo homem, ou seja, através da Linguística foi possível produzir certo conhecimento sobre a (s) língua (s), por meio de uma teoria. É o próprio Saussure (1999) quem diz "bem longe de dizer que é o objeto que precede o ponto de vista, diríamos que é o ponto de vista que cria o objeto" (SAUSSURE, 1999, p. 15).

Estamos falando, especificamente, do objeto de conhecimento, pois este, como nos diz Henry (1992),

é objeto que muda, que tem uma história inscrita na história da ciência da qual é objeto, na confrontação de suas teorias, nas práticas específicas que o caracterizam, assim como nas condições históricas que produziram essa história, essas confrontações, essa prática. (HENRY, 1992, p. 16)

\footnotetext{
5 De nossa perspectiva, não acreditamos que fazer a história da Linguística seria admitir que ela (a Linguística) é só uma totalidade dos momentos de seu desenvolvimento. Sobre esta questão ver Auroux (2014, p. 13).
} 
Sob o efeito de unidade e da cientificidade, a Linguística constrói seu objeto de conhecimento. Esses efeitos são produzidos ideologicamente, visto que o discurso da Linguística se constitui num processo de produção de conhecimento, numa forma de apropriação do objeto real pelo conhecimento.

O problema para Henry (1992) está em ignorar essa apropriação do objeto real pelo conhecimento e tomá-la como uma prática "espontânea". O autor afirma-nos que "essa é mais uma maneira de contornar a contradição objeto real-objeto de conhecimento ou, mais exatamente, de produzir uma apropriação ignorando-a ao mesmo tempo" (HENRY, 1992, p. 18).

A seguir, faremos algumas considerações, acerca da teorização de Chomsky, a fim de nos deslocarmos desse cientificismo empírico que, na verdade, é efeito de sentido produzido pela ideologia que está funcionando na prática discursiva (teórica) desse autor. Para isso, apoiaremo-nos nos estudos realizados por Henry acerca da pressuposição e a configuração epistêmica da Linguística. Procuraremos apreender dos estudos deste autor, questões referentes às teorias linguísticas e à constituição de suas ideias, a fim de compreendermos o processo histórico-ideológico subjacente a estas ideias.

O empirismo presente no discurso de Chomsky é explicitado com a intuição linguística do sujeito falante. Segundo Henry (1992), esta noção de intuição, referindo-se a Chomsky, intervém em dois níveis, em um nível prático e um nível teórico:

No nível prático, trata-se inicialmente de poder decidir se tal ou tal forma, construída a partir de elementos tomados como fazendo parte da língua, em função de regras tomadas como fazendo parte da gramática, pertence ou não à língua. [...] No nível teórico, dá-se a essa intuição um fundamento, que é a competência linguística. (HENRY, 1992, p. 19)

Esta noção de intuição linguística intervém na teorização de Chomsky como fazendo parte da produção do conhecimento científico deste autor e da legitimação da prática do linguista sobre a linguagem.

Ainda segundo Henry (1992), é interessante observar que a prática de construção de elementos de uma gramática, tal como concebe Chomsky, não opera fora da teoria, numa relação especular com o real que ela apenas revelaria.

Acerca do funcionamento do conceito de intuição na teoria de Chomsky, Henry (1992) vai nos dizer,

Em outras palavras, essa noção representa na prática do linguista, no quadro dessa teoria, uma apropriação da contradição entre objeto real e objeto de conhecimento, mas trata-se de uma modalidade de apropriação que tem por característica desconhecer seu objeto (a contradição) substituindo-o por um outro. $\mathrm{O}$ apelo aos fatos pelo viés da intuição linguística é na realidade um apelo a evidências e representações ideológicas: evidência do sentido, evidência da individualidade do sujeito enquanto unidade de uma interioridade singular e de sua universalidade. (HENRY, 1992, p. 20) 
Nessa sequência, entendemos, discursivamente, o sentido do conceito de intuição na teoria de Chomsky, ou seja, entendemos o que está subjacente a este conceito nesta teoria. A prática teórico-científica de Chomsky não é uma prática espontânea, tampouco é uma prática que se dá fora da ideologia. É dessa forma que compreendemos o discurso da teoria linguística de Chomsky, considerando o objetivo central desse nosso artigo.

Feitas essas considerações a respeito da teoria linguística de Chomsky, enfatizaremos o que entendemos por prática científica, com base também em Henry (1992):

ocorre que, do ponto de vista do materialismo histórico, o processo de produção do conhecimento, enquanto processo histórico, realiza-se concretamente sob formas históricas variadas, nas práticas sociais, principalmente no que chamamos a prática científica. (HENRY, 1992, p. 22)

Desse modo, a produção de conhecimento se dá sob determinadas condições históricas, não sendo, portanto, a teorização uma prática espontânea realizada por um sujeito também autônomo que se apropriaria de um objeto real (empírico). De nossa perspectiva, e remetendo-nos a Henry (1992), podemos assim compreender esta questão:

Dizer que esses agentes agem na e sob a determinação das formas históricas de existência é dizer que eles são constituídos em sujeitos nas práticas sociais e por elas. No que concerne aos agentes do processo de produção de conhecimentos, eles se constituem na prática científica e por essa prática como sujeitos, cientistas, pesquisadores, pensadores, que descobrem, sabem, pensam etc... Ora, precisamente, são formações ideológicas que constituem indivíduos concretos, agentes de práticas sociais, em sujeitos: 'só há prática através de uma ideologia' e 'só há ideologia por e para sujeitos'. (HENRY, 1992, p. 23)

Em, "Há uma via para a Linguística fora do logicismo e do sociologismo?", Pêcheux e Gadet (1998), já no início do texto nos alerta para a questão da contradição que na história da Linguística toma sucessivamente múltiplas formas:

o título que demos a esta comunicação traduz que, segundo nós, a própria história da Linguística pode ser compreendida como uma espécie de luta entre duas vias - o logicismo e o sociologismo formando os elementos de uma contradição que toma sucessivamente múltiplas formas, desde a pré-história da Linguística até seus aspectos mais modernos, mais atuais e mais científicos. (PÊCHEUX \& GADET, 1998, p. 5)

Essa contradição (ou esses elementos contraditórios) não é sentida como tal, "contenta-se em afirmar que a Linguística comporta aspectos diversos e variados, e eventualmente complementares em na sua diversidade" (PÊCHEUX \& GADET, 1998, p. 5). 
Os autores também nos chamam à atenção para outro fato, o de que esta contradição pode ser explicitada. Ou seja, segundo estes autores, esta contradição oculta poderá se tornar aparente, na medida em que se reconhece a existência de um elemento (também ele recoberto pela "neutralidade" científica da Linguística) que é a filosofia espontânea dos linguistas. (PÊCHEUX \& GADET, 1998, p. 6)

É preciso desmontar as várias figuras da ideologia que vão sendo requisitadas pela Linguística sob a evidência de uma aliança natural, quando, na verdade, elas são as formas da ideologia que recobrem a contradição, evitando com isso que a própria contradição seja trabalhada. Estas figuras ideológicas estão significando sob efeitos de sentidos diversos: o biologismo, o psicologismo, o sociologismo, o empirismo, o positivismo, etc. Dessa forma, Althusser (1991), referindo-se à "invasão" dessas ideologias tanto na psicanálise quanto no marxismo, vai nos dizer que "elas são, cada uma a seu modo, efetivações de uma mesma tendência, que é o idealismo da ideologia dominante burguesa [...]" (ALTHUSSER, 1991, p. 57).

Ainda sobre esta questão, Pêcheux e Gadet (1998) vão afirmar que estes elementos contraditórios, o logicismo e o sociologismo,

conduzem atualmente a Linguística a uma crise, a uma espécie de impasse. No entanto essa contradição não se impõe à evidência na medida em que, a maior parte das vezes, ela não é sentida como tal. (PÊCHEUX \& GADET, 1998, p. 5)

Pêcheux e Gadet (1998), ainda sobre o ocultamento/apagamento da contradição no domínio da Linguística, vão nos dizer que:

assistimos, com efeito, à produção de conceitos científicos mas, e isto é significativo, aquilo contra o que se constituíram esses conceitos continua a existir e a produzir efeitos na pesquisa: é assim para o corte saussuriano, é assim para as críticas construtivas que Chomsky endereçou às gramáticas estruturalistas. Não podemos, pois, levar em conta só a história da Linguística, temos de levar igualmente em conta o que chamamos de filosofia espontânea dos linguistas [...]. (PÊCHEUX \& GADET, 1998, p. 6)

Para estes autores, esta filosofia espontânea dos linguistas explica a perpetuação destas contradições, ainda que de forma transformada.

Estas duas tendências (o logicismo e o sociologismo), dizem os autores (idem), não são puras, evidentemente, não se realizam de forma absoluta, elas são apenas dominantes, "sendo que numerosas formas intermediárias que poderíamos chamar de 'compromissadas' têm como pretensão servir de paliativo das insuficiências de uma tendência pela outra" (PÊCHEUX \& GADET, 1998, p. 6).

Duas questões, podemos levantar, segundo a linha de reflexão dos autores que aqui mencionamos: Por que essa divisão do trabalho teórico se dá dessa forma, constitui- 
se sob, principalmente, a dominância dessas duas tendências? Por que a divisão deste trabalho teórico se constitui sob a evidência/aparência de duas tendências contraditórias?

Acreditamos que para respondermos a estas questões é preciso mudar de terreno, como bem observa Orlandi (1998):

ao mesmo tempo em que se faz necessária uma desubjetivação da teoria da linguagem - e aí a noção de língua é fundamental - é preciso considerá-la como base comum de processos discursivos diferenciados. Para isso, há necessidade de uma mudança de terreno que não reduz a inclusão do sujeito, da história e da sociedade a um simples apêndice de uma reflexão já feita pela Linguística ou pelas Ciências Sociais. (ORLANDI, 1998, pp. 3-4)

Em relação às questões que nos colocamos neste artigo, compreendemos que as teorias linguísticas recobrem as relações de produção (e de reprodução) e as lutas ideológicas ao se apresentarem como filosofias espontâneas.

Portanto, a (s) língua (s) é o objeto de estudo da Linguística, e este objeto é construído a partir de uma teoria, ou seja, a constituição de um objeto de estudo está relacionada à sua teorização (objeto de conhecimento). Mas ela - com o tempo - passou a receber diferentes tratamentos pelos linguistas, ou seja, o terreno específico da Linguística começou a ser contextualizado, e disso decorreu em outras abordagens, provocando a redefinição deste objeto de estudo, tal qual ele foi configurado pela Linguística, por Saussure. E, aqui, não estamos entendendo o discurso da Linguística como um discurso uno (como tendo uma unidade), nem tampouco acreditamos que as teorias linguísticas se constituíram de forma contínua, cumulativa, linear, sucessiva ${ }^{6}$. Dessa forma, o que tematizamos nesse trabalho é o fato de podermos compreender as teorias linguísticas como efeito de sentidos, considerando a determinação histórica dos processos de constituição das ideias linguísticas.

Por esta via, incorporaram-se aos estudos linguísticos, a realidade psicológica, a realidade social, a lógica etc. (filosofias espontâneas). No entanto, no campo epistemológico, Pêcheux e Gadet (2004) encaram essa trajetória da Linguística como uma forma de extensão, uma forma de abandono de seu objeto próprio - que é o real da língua -, uma forma de surdez interna, numa dura crítica à Linguística e às certezas a que ela cedeu. Os autores vão dizer que a Linguística sucumbe às realidades psicossociológicas dos atos de linguagem. Ou em outras palavras, criticam o método científico e o trabalho linguístico que ele impõe, que constitui o sintoma dessa surdez, ao buscar realizar um estudo cego que não faz intervir as questões da ordem própria da língua:

o que, então, a linguística foraclui no interior de si mesma? Nosso empreendimento é recuperar (através das escolas, das teorias e das problemáticas que marcam sua história) as recorrências que, pela organização que impõem ao trabalho linguístico e pelo regime de funcionamento científico que determinam para esse trabalho, são o

\footnotetext{
${ }^{6}$ Essa posição de produzir conhecimento não levaria em conta a luta ideológica, dissimulando a história real das ciências.
} 
sintoma dessa insistência no ensurdecimento. (GADET \& PÊCHEUX, 1994, p. 19)

Ao refletir criticamente sobre as ilusões e o idealismo que recobrem o discurso da Linguística, Pêcheux propõe uma nova teoria, com seu método e seu objeto próprios que leve em consideração o real da língua, a ambiguidade ${ }^{7}$, a falha, o equívoco que lhes são inerentes. Trata-se da Análise de Discurso.

Dessa forma, Pêcheux visa constituir um espaço teórico que reflita sobre a própria prática teórica e científica de produção de conhecimento sobre a língua, que leve em conta que esta prática teórica é uma prática ideológica. Só temos acesso ao conhecimento porque temos acesso à história do conhecimento. Orlandi (2004), na abertura da tradução A língua inatingível - o discurso na história da linguística, afirma que "é este o procedimento da análise de discurso em uma reflexão que se dá como objeto a elaboração de uma história da reflexão sobre a linguagem. É essa a análise de discurso que Michel Pêcheux propôs" (ORLANDI, 2004, p. 9).

No interior da própria Linguística, e também, de certa forma, determinados por ela, os estudiosos foram interpretando o seu objeto de estudo de formas diferentes, ora dentro de um cientificismo positivista (e idealista) que nada reflete sobre a própria prática ideológica, sob a qual a sua (da Linguística) prática teórico-científica se dá, ora dentro de um empirismo que vê a língua como um todo (como aquilo que está ou não está na língua), que numa investigação, a teoria revelaria esta língua . É contra esse discurso que Pêcheux direciona fortes críticas ao narcisismo e ao idealismo das teorias linguísticas que marcaram os desdobramentos da Linguística até metade do século XX.

Vale ressaltar que a Linguística não é um bloco fechado, impermeável que acumularia tendências que se complementariam. As teorias linguísticas, sob a forma de tendências, não deixam ver as disputas de sentidos, as lutas ideológicas, o que simula o efeito de uma ciência homogênea/una que estaria em evolução, sob o efeito de uma história contínua.

No entanto, as teorias linguísticas não são evidentes, transparentes, quando nos perguntamos pelo efeito da ideologia subjacente a elas. Assim, compreendemos que aquilo que aparece como natural, é, na verdade, o funcionamento da ideologia que pode ser reconhecido na prática discursiva (científica) dessas teorias.

Esse movimento das teorias linguísticas não se dá espontaneamente, ele é determinado histórica e ideologicamente. Não temos uma visão continuísta da história da Linguística.

O discurso científico da Linguística, e uma vez inscrito nele, regula até onde o sujeito-linguista ${ }^{8}$ poderá chegar em suas reflexões. A prática científica como qualquer outra prática social, dá-se sob determinadas regras que cerceiam o que o sujeito-

\footnotetext{
${ }^{7}$ Ambiguidade aqui não está sendo tomada no sentido lógico-semântico.

${ }^{8}$ A inserção da noção de sujeito, teoricamente falando, foi o que possibilitou, principalmente, a mudança de terreno promovida pela teoria da análise de Discurso.
} 
pesquisador/cientista pode ou não dizer. Mais que isso, a prática científica promove/eleva o dizer à condição de produção de conhecimento, mas isso não se dá fora das lutas ideológicas. A prática científica é uma prática histórica que legitima um dizer, instituindo um espaço em que se naturalizam as "ideias", as "reflexões". Estas considerações têm o objetivo de provocar para novas discussões tendo em vista o estudo da especificidade de cada teoria linguística e dos efeitos de sentidos por elas sustentados. Desse modo, interessa-nos, da perspectiva de que estamos falando, a história real dessas teorias linguísticas, ou seja, o discurso que elas produzem.

Dessa forma, segundo Pêcheux (2004), a Linguística não mexe em suas feridas, e, ao invés disso, vai estendendo seu domínio (ao invés de trabalhar as contradições) e se mostrando surda à sua própria história. Escutar o "real" da língua, suas falhas, seus equívocos, como sendo constitutivos dela, é o que levou Pêcheux (idem) a outra compreensão de seu objeto de estudo.

\section{Não existem ideias linguísticas na "minha cabeça"}

Discursivamente falando, os estudos efetuados sobre a língua olham para este objeto dentro já de certo "realismo", ou seja, partem de um objeto imaginário, de seus efeitos de sentidos (a realidade evidente deste objeto), de um objeto já interpretado (eles não se interessam pela constituição de seu objeto), mas acreditam estar descrevendo-o em si mesmo, já que são pegos por esta evidência (a ilusão referencial, conforme nos diz Pêcheux, 1995), isto é, reproduzem esta evidência ideológica, e que, a todo tempo, eles se deparam com obstáculos (entram em contradições ${ }^{9}$ ), mas que logo cuidam de eliminálos, pois estes são considerados "erros" / "equívocos" (dificuldades) e devem ser superados.

Estes estudos não consideram a constituição histórico-ideológica inerente ao seu objeto de estudo: a língua. Em outras palavras, estes estudos ficam em uma análise empírica $^{10}$ do objeto. Dessa posição, a empírica, o objeto real é reflexo direto de uma realidade. Eles se iludem com seus objetos. Desse modo, criaram-se teorias em torno da língua, cada uma segundo o seu recorte. Não acreditamos que estas teorias realizam/realizaram um estudo "neutro" e "imparcial" sobre a língua. Algumas destas

\footnotetext{
${ }^{9}$ A contradição aqui não é tematizada no sentido lógico. Ela é tomada no sentido (discursivo) daquilo que trabalha e interroga o que é próprio da língua, e que está sujeito à falha, ao equívoco. Mas, que no discurso da Linguística vemos a contradição sendo recoberta por um sentido de fechamento, de completude da língua.

10 A filosofia empirista valorizava a experiência como fonte de conhecimento. É pela experiência que se chega ao conhecimento. Remetemo-nos aqui também a Evangelista (1991) que traz o seguinte questionamento: "Mas o que é empirismo? Empirismo é identificar o objeto-real como o objeto-deconhecimento. É dizer que o objeto-de-conhecimento, que a essência está no objeto-real, de uma maneira ou de outra. Empirismo é conceber o processo do conhecimento como uma modalidade de extração da verdade a partir do real. Assim como Marx não chegou ao conceito de "mais-valia" abstraindo esse conceito da realidade da exploração capitalista, Freud não chegou ao conceito de "inconsciente" abstraindo esse conceito da realidade do modo de ser humano neurótico ou psicótico" (1991, p. 35).
} 
disciplinas são puramente "experimentais", pois partem do observável, portanto, de uma realidade empírica.

Com isso, queremos dizer que a teorização já é uma interpretação. Não existe prática discursiva a não ser sob uma ideologia. Desse modo, as questões que nos colocamos são: sob quais ideologias Saussure, Martinet, Chomsky entre outros produziram suas teorizações? Suas práticas científicas se inscrevem em quais formações discursivas? Em seus discursos estão representadas quais ideologias? Isso é um fato ${ }^{11}$. E não seria diferente com as práticas científicas. Somente com outros trabalhos, que poderíamos levar adiante o estudo dessas questões.

Por ora, podemos apenas afirmar que em uma certa teorização estão funcionando certas ideologias e não outras.

Estas teorias desejam superar seus "problemas", suas "deficiências". Trata-se do idealismo (da vontade de uma verdade, de fechamento), da busca de uma verdade, da tentativa de "apaziguar" essa tensão, em outras palavras, elas são constituídas dentro de um idealismo. Dessa maneira, e considerando essa filosofia idealista, elas estão sempre na ilusão de que partem de um objeto concreto (que existe na sua "essência"), único, homogêneo que vai determinar suas análises (o objeto determina a análise).

Sobre esta questão, é importante lembrarmos de que Saussure, por exemplo, de outra perspectiva, faz trabalhar em seu discurso a ideia de que é o ponto de vista que cria o objeto. O que isso significa no discurso científico desse autor? Parece-me que ele reconhece a necessidade de estabelecer um método teórico para o estudo do objeto. Ele afirma que o objeto não será mais o mesmo quando se fala deste ou daquele prisma (BENVENISTE, 1995, p. 42). A língua não oferece nenhuma substância, diz Saussure. Benveniste (1995) mostra esse posicionamento de Saussure na sequência que transcreveremos abaixo:

É claro que se pode tomar como objeto da análise linguística um fato material, por exemplo um segmento de enunciado ao qual não se prenderia nenhuma significação, considerando-o como simples produção do aparelho vocal, ou mesmo uma vogal isolada. Acreditar que temos aí uma substância é ilusório; é precisamente e apenas por uma operação de abstração e de generalização que podemos delimitar semelhante objeto de estudo. Saussure insiste nisso: é só o ponto de vista que cria essa substância. (BENVENISTE, 1995, p. 44)

A Linguística, enquanto a ciência da linguagem, constitui-se no espaço da cientificidade em que temos o positivismo do século XIX um fator determinante. Podemos dizer que Saussure realiza o seu gesto de interpretação (ORLANDI, 1996), ao delimitar seu objeto de estudo e definir seu método teórico, tendo em vista este préconstruído de ciência marcado pelos sentidos (pré-) estabelecidos pelo positivismo.

${ }^{11}$ A presença das ideologias em qualquer prática discursiva. 
Há diferenças importantes a serem analisadas em relação à constituição dessas teorias linguísticas no que se refere a suas filiações teóricas (positivista, empirista, logicista, materialista etc.) que devem ser explicitadas.

Não se pode negar ou ignorar o fato de que muitos estudiosos já pensaram este objeto (a língua), no campo da Linguística. No entanto, este objeto é concebido por diferentes teorizações que, se consideradas em suas evidências, não nos permitirá apreender a relação entre discurso (prática discursiva), sujeito e ideologia, o que produzirá um apagamento das determinações histórico-ideológicas subjacentes a essas práticas. Mais que isso, ficando na evidência dessas teorizações, cairíamos no reducionismo e no generalismo de que a Linguística é uma ciência una/homogênea e que essas teorizações se completariam ou se acumulariam numa linha cronológica, diluindo-se, dessa forma, a singularidade/ a especificidade das ideias linguísticas. Não há encadeamentos (lógicos) das teorias. Todas essas teorizações configuraram certa memória para este objeto, uma produção de conhecimento sobre a língua. Em outras palavras, podemos chamar de um arquivo do conhecimento científico, do discurso da ciência (GUIMARÃES \& ORLANDI, 2006, p. 143).

Dessa forma, falar de uma determinada maneira de produzir conhecimento sobre este objeto não pode, de maneira alguma, de nosso ponto de vista, fechar os olhos para as outras formas de conhecimento já existentes. Isto porque não se pode recobrir teorias, e nem as compreender como complementares, o que levaria a uma compreensão idealista da prática científica. Tudo o que já foi falado sobre a língua, configura uma memória discursiva deste objeto, conforme já dissemos. E isso também determina o que será feito e o próprio sujeito dessa prática científica. Os conceitos ${ }^{12}$ sob os quais uma teoria se sustenta não são neutros, eles já recortam o olhar sobre o objeto, problematizando-o e visando (limitando já) responder às questões feitas ao objeto dentro deste recorte. A relação que uma determinada teoria mantém com seu objeto de estudo é o que vai definir esse corpo de conceitos ${ }^{13}$. Vemos, então, que é o objeto em si (isto em uma perspectiva empirista) que se acredita estar descrevendo, quando, na verdade, se está no seu imaginário. É a confusão, conforme Pêcheux e Fichant (1989, p. 117), entre o real e o conhecimento, num estilo empirista, que confere ao conhecimento as propriedades do real. O que para nós se trata de uma prática, que é ideológica, do sujeito.

Sob a teoria científica de Saussure, como já dissemos, efeitos de sentidos são produzidos, garantindo a cientificidade (com a elaboração de um objeto de estudo próprio e da produção de um conhecimento) e a unidade desse discurso, em outras palavras, tratase do processo de constituição de evidências científicas.

Acreditamos que os apontamentos de Evangelista (1991), acerca da reflexão de Althusser (1991) sobre o caráter científico da psicanálise e do marxismo, em Freud e Lacan/Marx e Freud, são de suma importância para entendermos a discussão que estamos

\footnotetext{
12 Ver sobre esta noção, estudo sobre a história dos conceitos, conforme Lecourt (1980, p.65).

13 Pêcheux \& Fichant (1989) vão dizer que "uma ciência não nasce da definição de um objeto, nem do encontro com um objeto, nem de imposição de um método. Nasce da constituição de um corpo de conceitos, com as suas regras de produção. Por esta mesma razão o devir de uma ciência é a formulação dos conceitos e das teorias desta ciência" (PÊCHEUX \& FICHANT, 1989, p. 113).
} 
trazendo aqui neste artigo em torno do discurso das teorias linguísticas e de seus recobrimentos que se configuram na evidência de tendências pouco sustentáveis, quando se pensa a história da constituição dessas ideias. Seguimos, então, fazendo algumas considerações sobre as noções de objeto real-objeto de conhecimento, pensando nossas próprias questões neste artigo.

Nesse sentido, acreditamos que esta busca pela compreensão (pelo conhecimento) do objeto não seja tão direta assim como se imagina, pois se trata da contradição entre o objeto real e o objeto do conhecimento, como nos diz Evangelista (idem). Este autor, que faz a introdução crítico-histórica do livro (do qual também é o tradutor) Freud e Lacan/Marx e Freud, de Althusser (1991), vai nos dizer: "Ora, o objeto de uma ciência, enquanto objeto-de-conhecimento, ou seja, um objeto produzido teoricamente, não pode ser simplesmente apontado como a primeira realidade empírica vinda" (EVANGELISTA, 1991, 12). A passagem seguinte, formulada por Althusser (1991 apud EVANGELISTA, 1991, pp.35-36), constitui a base para toda a reflexão que fazemos aqui neste texto: "O conhecimento científico é uma forma de apropriação do objeto real pelo objeto de conhecimento". Ainda sobre esta importante questão que problematiza essa relação entre o objeto-real e o objeto-de-conhecimento, Evangelista (idem) vai pontuar:

Logo, o que faz com que uma ciência exista não é apenas a existência de um real, de um objeto real. Uma ciência existe quando ela produz um objeto-de-conhecimento capaz de se apropriar do real. O que caracteriza uma ciência é o fato de ela ter sido capaz de construir, com seus conceitos rigorosamente definidos, o seu objeto-de-conhecimento. (EVANGELISTA, 1991, p. 36)

Desse modo, podemos, a partir dessas falas, chegar a algumas hipóteses em nossas discussões. O teórico nunca é o real, ele é um lugar para se pensar e falar do real. A descrição do objeto se dá de acordo com a imagem que fazemos dele ou de uma "parte" dele, pois, o objeto real nós não o conhecemos, apenas nos deparamos com ele. Olhamos para o nosso objeto por um ângulo que muitas vezes não nos damos conta desta interpelação ou filiação. É preciso certo procedimento para a produção do conhecimento. As teorias, desta perspectiva, produzem determinado conhecimento sobre o objeto real, a partir de um método que já o recorta. Não nos relacionamos com o objeto real, mas sim com suas representações, isto é, com suas interpretações. Através da teoria, chegamos no objeto de conhecimento. Abandona-se a ideia ou a ilusão da descrição de um objeto total. O método está inscrito no próprio modo de enunciação dos conceitos, das descrições, etc. Dessa posição, ao contrário, pensa-se que é a teoria que constrói o objeto. Ou seja, a partir de uma posição ideológica, certo conhecimento será produzido, respondendo às perguntas formuladas dentro dessa formação ideológica.

A definição, o delineamento do objeto de uma ciência não se reduz à evidência de uma realidade empírica, mas sim da constituição teórica deste objeto. O fato de se conceber a língua de uma forma e não de outra, é uma questão ideológica, pois envolve uma interpretação e sabemos de acordo com Orlandi (1996) que não há interpretação sem ideologia. E a Linguística caminha "cega" neste ponto. Desse modo, a teorização de certo objeto obedece a princípios rigorosos, que podemos chamar de regularidades discursivas (Foucault, 2009), pois cerceiam o que se vai dizer (ou não) acerca de tal objeto e também 
possibilitam distinguir uma teoria de outra. São estas questões levantadas aqui que entram em jogo na constituição de uma teoria e de seu objeto de conhecimento.

Nossa reflexão vai na direção de discutir sobre o processo de constituição de uma teoria, instalando e reafirmando a existência da ideologia nesse processo de teorização, concluindo que toda ciência é uma prática teórica, que se constitui sob uma ideologia, não sendo, portanto, uma ciência que se constitui por si e para si mesma, negando a ideologia. Dessa forma, não separamos ciência de ideologia, nem teoria de prática.

Pêcheux critica o projeto da Linguística dizendo que:

não cessou, desde a origem, de se negar através de uma alternância de diásporas reais e de reunificações enganosas, remetendo, talvez no pensamento do genebrino, à inclinação interna de seu autorecobrimento. (PÊCHEUX, 1999, p. 9)

A Linguística vai fazendo alianças, como já foi afirmado aqui, que vão desviandoa de suas questões fundadoras, e que a fizeram cair em tendências psicologistas, empiristas, sociologistas e logicistas, resultando na perda do que seriam as ideias próprias de Saussure (como disse Benveniste (1995): "e Saussure ficava sozinho com seus problemas...”).

Sobre essa colocação de Benveniste, é interessante observar que ele se referia, a meu ver, ao projeto de Saussure de ter realizado um corte epistemológico nos estudos da linguagem, por ele ter pensado contra seu tempo, uma vez que buscava, não a origem da linguagem ou suas determinações de ordem biológica, lógica ou filosófica, mas aquilo que constitui propriamente a língua (Pêcheux, 1999 apud DIAS, 2003).

De fato, Benveniste vai nos dizer que

os linguistas estavam tão absorvidos num grande esforço de investigação histórica no emprego dos materiais de comparação e na elaboração de repertórios etimológicos. Esses grandes empreendimentos, afinal muito úteis, não deixavam lugar às preocupações teóricas. E Saussure permanecia sozinho com os seus problemas [...]. (BENVENISTE, 1995, pp. 41 e 42)

Saussure sabia que precisava definir sua teoria para que ela se instituísse, constituindo-se, dessa forma, em referência para os linguistas, enfim, como diz Benveniste (1995), era necessário teorizar o que um linguista faz.

Considerando o desdobramento da Linguística no século XX, Pêcheux (1999) vai assinalar as diferentes interpretações (sociologistas, logicistas ou psicologistas) que se incorporaram ao projeto de conhecimento da língua, de Saussure, concluindo que o seu projeto não se cumpriu.

O que estamos fazendo aqui é interrogar o modo pelo qual estas teorias se constituíram, em outras palavras, queremos compreender como estas teorias acabaram 
por reproduzir um discurso de ordem positivista biopsicofuncional, porque aderiram às tendências sem questioná-las ou negá-las. À língua é incorporada a ideia de instrumento de comunicação, concepção esta que não faz trabalhar os efeitos materiais (as relações de sentidos) e as falhas e os equívocos da língua.

Daí o nosso interesse pela Análise de Discurso, por se tratar de uma teoria materialista que busca compreender os discursos enquanto processos históricos de produção de sentidos, determinados pelas relações de produção estabelecidas ideologicamente.

E, em relação à reflexão que a Análise de Discurso se autopromove no bojo dessas relações, isto constitui, a meu ver, sua principal marca de nascença, fruto das condições histórico-políticas em que ela se originou. É este o método que a Análise de discurso desenvolve e que lhe permite compreender o processo de constituição de um discurso, inclusive de seu próprio discurso, o que a coloca num lugar muito específico no domínio das ciências humanas e sociais, isto é, num lugar de entremeio, por trabalhar nas fronteiras das regiões disciplinares, elaborando suas contradições, ou seja, refletindo sobre essas relações teóricas contraditórias constitutivas.

A teoria da Análise de Discurso não cai nessas armadilhas (o idealismo, o empirismo, o psicologismo, o positivismo, etc.) ao definir seu objeto de estudo. Pelo contrário, ela se constitui em uma disciplina que critica essas tendências acolhidas pelas teorias de linguagem. Ela permite ver fronteiras e trabalha com a contradição, com a falha, com o equívoco, com a falta. Em Análise de Discurso, falamos em construção discursiva dos referentes. A Análise de Discurso vai, em seus pressupostos teórico-metodológicos, criar uma teorização específica acerca da língua, partindo de uma conceituação em que a língua é definida como sendo uma base material para a realização dos processos discursivos, ou seja, trata-se de considerar a materialidade da língua. Enfim, chegamos no que é a produção teórica desta disciplina - a construção de seu objeto-deconhecimento.

\section{Conclusão}

Nossa preocupação principal, ao elaborarmos este texto, foi apresentar uma reflexão que problematizasse os efeitos de sentido praticados pelas teorias linguísticas sob a transparência da linguagem e dos sujeitos, dando visibilidade às ilusões e as contradições que são constitutivas destas teorias.

De início, um deslocamento já se faz necessário. Essas teorias, como qualquer outra, não são simplesmente teorias, elas têm um funcionamento que é ideológico, ou seja, elas não são teorias por si e por elas mesmas, são práticas teóricas que se fazem por meio de e sob uma ideologia.

O que nós defendemos neste texto, e da posição que o fazemos, está representado nele pela nossa filiação teórica à Análise de Discurso, teoria esta que nos permite 
compreender este "gesto de interpretação", inerente ao sujeito do discurso, que nos leva a comprometermos com certos sentidos e não outros. E isto, é claro, também está presente na produção discursiva científica, o que não significa que a Análise de Discurso estaria fora da ideologia, da interpretação, porque ela, decididamente, não está. Não existe exterior à ideologia. Portanto, dessa posição, da Análise de Discurso, estamos expostos a compreender como os discursos funcionam, como os sentidos se constituem, sem negarmos os efeitos materiais da ideologia.

Dessa forma, nosso estudo se inscreve num modo de pensar a linguagem e a teorização sobre ela encontradas, como já dissemos, na teoria da Análise de Discurso, de linha francesa, na perspectiva de Michel Pêcheux e aqui no Brasil, de Eni Orlandi, articulada ao método da História das Ideias Linguísticas.

Foi por esta via que conseguimos elaborar algumas inquietações concernentes às teorias linguísticas até chegarmos a uma teorização própria da Análise de Discurso e de seu objeto de estudo.

O percurso que realizamos buscou enfatizar que a Análise de Discurso parte do corte epistemológico efetuado por Saussure para instalar a problemática do real da língua, recoberto pelas teorias linguísticas ao se constituírem sob tendências formalistas, sociologistas, enunciativas que acabam por não interpretar o funcionamento próprio dessas ideias, na teorização que fazem sob o evidente efeito ideológico.

Também a Análise de Discurso se constitui em uma forma de conhecimento, que em sua constituição, encontramos a Linguística. Desse modo, compreendemos que seja necessário trabalhar o processo histórico da construção de suas ideias, para observarmos a mudança de terreno que, de fato, ela instaura nos estudos dessas teorias linguísticas, ao pensar a língua como a base para a realização dos processos discursivos. E aí, teríamos matéria para a escrita de outro texto, em torno de uma questão provocativa e longe de ser tranquilo o caminho a ser trilhado...

Por fim, com este artigo, pretendemos enfatizar o caráter material das ideias, ao enfocarmos que uma teorização é uma prática político-ideológica e que, portanto, a produção do conhecimento deve ser considerada na sua relação com a história, com o sujeito e com a ideologia, condições materiais para a sua real existência.

\section{Referências bibliográficas}

ALTHUSSER, L. Freud e Lacan/Marx e Freud. Rio de Janeiro: Edições Graal, 1991.

BALDINI, L.J.S. Frege e Hussel: a questão do pressuposto. Línguas e instrumentos linguísticos, 27 e 28, Jan/Dez 2011. Campinas, Universidade Estadual de Campinas, Editora RG, 2011. 
BENVENISTE, É. Saussure após meio século. Em: Problemas de linguística geral I. Campinas: Pontes, 1995.

DIAS, L.F. Resistência e desafio: traços do pensamento de Pêcheux no Brasil. Em: Painéis, Anais do I SEAD [Seminário de Estudos em Análise de Discurso, recurso eletrônico], Porto Alegre, UFRGS, 2003.

EVANGELISTA, W.J. Introdução: Althusser e a psicanálise. Em: ALTHUSSER, L. Freud e Lacan/ Marx e Freud. Rio de Janeiro: Edições Graal, 1991.

FOUCAULT, M. A arqueologia do saber. Rio de Janeiro: Forense Universitária, 2009.

HENRY, P. A ferramenta imperfeita: língua, sujeito e discurso. Campinas: Editora da Unicamp, 1992.

LECOURT, D. Para uma crítica da epistemologia. Lisboa: Assírio e Alvim, 1980.

NUNES, J.H. Uma articulação da análise de discurso com a história das ideias linguísticas. Letras, nº 37, Santa Maria, v. 18, nº 02, 107-124, jul./dez. 2008.

ORLANDI, E.P. Nota introdutória do tradutor. Escritos [Linguagem, Cidade, Política, sociedade - Discurso e Política], nº 3, LABEURB, NUDECRI, 1998. 1996.

Interpretação: autoria, leitura e efeitos do trabalho simbólico. Petrópolis: Vozes,

PÊCHEUX, M. Sobre a (des-) construção das teorias linguísticas. Língua e instrumentos linguísticos, $\mathrm{n}^{\mathbf{0}}$ 2, Campinas, Pontes, Julho-Dezembro 1999.

. Há uma via para a Linguística fora do logicismo e do sociologismo? Em: Escritos [Linguagem, Cidade, Política, sociedade - Discurso e Política], $\mathrm{n}^{\mathbf{0}} 3$, LABEURB Laboratório de Estudos Urbanos - NUDECRI, 1998.

. Semântica e discurso: uma crítica à afirmação do óbvio. Campinas: Editora da Unicamp, 1995.

; GADET, F. A língua inatingível: o discurso na história da linguística. Campinas: Pontes, 2004.

; FICHANT, M. Sobre a história das ciências. São Paulo: Mandacaru, 1989.

SAUSSURE, F. Curso de linguística geral. São Paulo: Cultrix, 1999. 


\section{$* * *$}

Artigo recebido em: janeiro de 2017.

Aprovado e revisado em: março de 2017.

Publicado em: abril de 2017.

\section{Para citar este texto:}

FRAGOSO, Élcio Aloisio. O ponto de vista determina o objeto: uma leitura materialista possível do objeto de estudo concebido por Saussure em sua teorização. Entremeios [Revista de Estudos do Discurso, on-line], Seção Estudos, Programa de Pós-Graduação em Ciências da Linguagem (PPGCL), Universidade do Vale do Sapucaí (UNIVÁS), Pouso Alegre (MG), vol. 14, p. 149-166, jan. - jun. 2017.

DOI: http://dx.doi.org/10.20337/ISSN2179-3514revistaENTREMEIOSvol14pagina149a166 